\title{
THE SYSTEM OF TRACKING THE POSITION OF THE BUCKET EXCAVATOR'S WHEEL FOR PREVENTION OF RISK SITUATIONS
}

\author{
Roman KAPICA $^{1)}$, Dana VRUBLOVÁ ${ }^{2)}$ and Martin VRUBEL ${ }^{3)}$ \\ 1) V̌̌B - Technical University of Ostrava, Faculty of Mining and Geology, 17. Listopadu 15/2172, 70833 Ostrava-Poruba, Czech Republic \\ 2) VŠB - Technical University of Ostrava, Faculty of Mining and Geology, Dělnická 21, Most, Czech Republic \\ 3) Surveying and Geology Department, Severočeské doly a.s., Chomutov, Czech Republic \\ *Corresponding author's e-mail: roman.kapica@vsb.cz
}

\begin{tabular}{l} 
ARTICLE INFO \\
\hline Article history: \\
Received 28 May 2018 \\
Accepted 3 September 2018 \\
Available online 12 September 2018 \\
\hline
\end{tabular}

\section{Keywords:}

Bucket Wheel Excavator

GNSS

Geology

Occupational safety

Opencast mining

Risk situations

\begin{abstract}
For companies doing business in mining mineral deposits, ensuring safe work is one of the key tasks (Safety First!). One of the important trends in this area is prevention and endeavour to forestall risk situations. Risks need to be searched, technically described, spatially defined, evaluated and categorized by degree of risk. Complex geological and stability conditions can be one of the sources of persistent and significant risks, which are mainly landslides and rockslides threatening both mining equipment and employees. The problem described in this article and its solution concerns the Most Basin (formerly the North Bohemian Lignite Basin). This is a tertiary basin that was founded in the Oligocene. The main mineral is lignite and mining takes place on the surface. The main excavating machinery in the surface lignite quarries in Europe (Czech Republic, Germany, Poland) is the bucket wheel excavator.
\end{abstract}

\section{INTRODUCTION}

A number of giant machine crashes have been documented, caused by landslides. Landslides result in various damages to excavators, injuries to the excavator operator, and the consequent need for shutdowns for repairs. To eliminate these risks, or at least to reduce their impacts, it is necessary to describe the geological structure of the deposit in as much as detail as possible, especially the tectonic disturbances and other geological structures which may cause landslides. These structures are then geometrized. The result must be a system of categorizing these elements into categories according to the degree of risk affecting the mining process. If the technical equipment for monitoring the position of excavators in the environment of the quarry digital model with the geological structures worked into it is simultaneously operated at the mining site, it is possible to evaluate the degree of danger to the excavator from the current excavator spatial position and to create an application that informs the excavator crew of the degree of danger in the real time. This allows, along with other measures, to eliminate the risks significantly.

\section{EXCAVATOR WHEEL TRACKING SYSTEM}

The system for calculation of the excavator's or the wheel's spatial position in the real-time consists of the following elements (Fig. 1, Vrublová et al., 2012; Sládková et al., 2011):

- Measuring segment - Trimble SPS 851 GNSS receivers for measuring the position of two points on the excavator in the S-JTSK (Datum of Uniform Trigonometric Cadastral Network) coordinate system and the altitude in Baltic Vertical Datum - After Adjustment (Bpv);

- $\quad$ SITALL Electronic inclinometers for measuring the inclination of the entire excavator and wheel boom; Incremental Speed Sensor (LARM a.s.) for measuring wheel boom extension,

- Communication segment - for the transmission of measured data to the OMG computer server (GPRS data transfer technology, radio modems),

- User segment - KVASoftware company's "Mining Model" evaluation software working with a "dynamic map", or a model describing the area affected by mining.

The individual components of the measuring system are designed to obtain the relevant input values for calculating the spatial position of the wheel centre in any position of the excavator and the wheel boom. At the same time, they must be placed in such a way that they do not restrict the operation of the excavator and, at the same time, their operation is not restricted by deteriorated operating conditions. The location of 

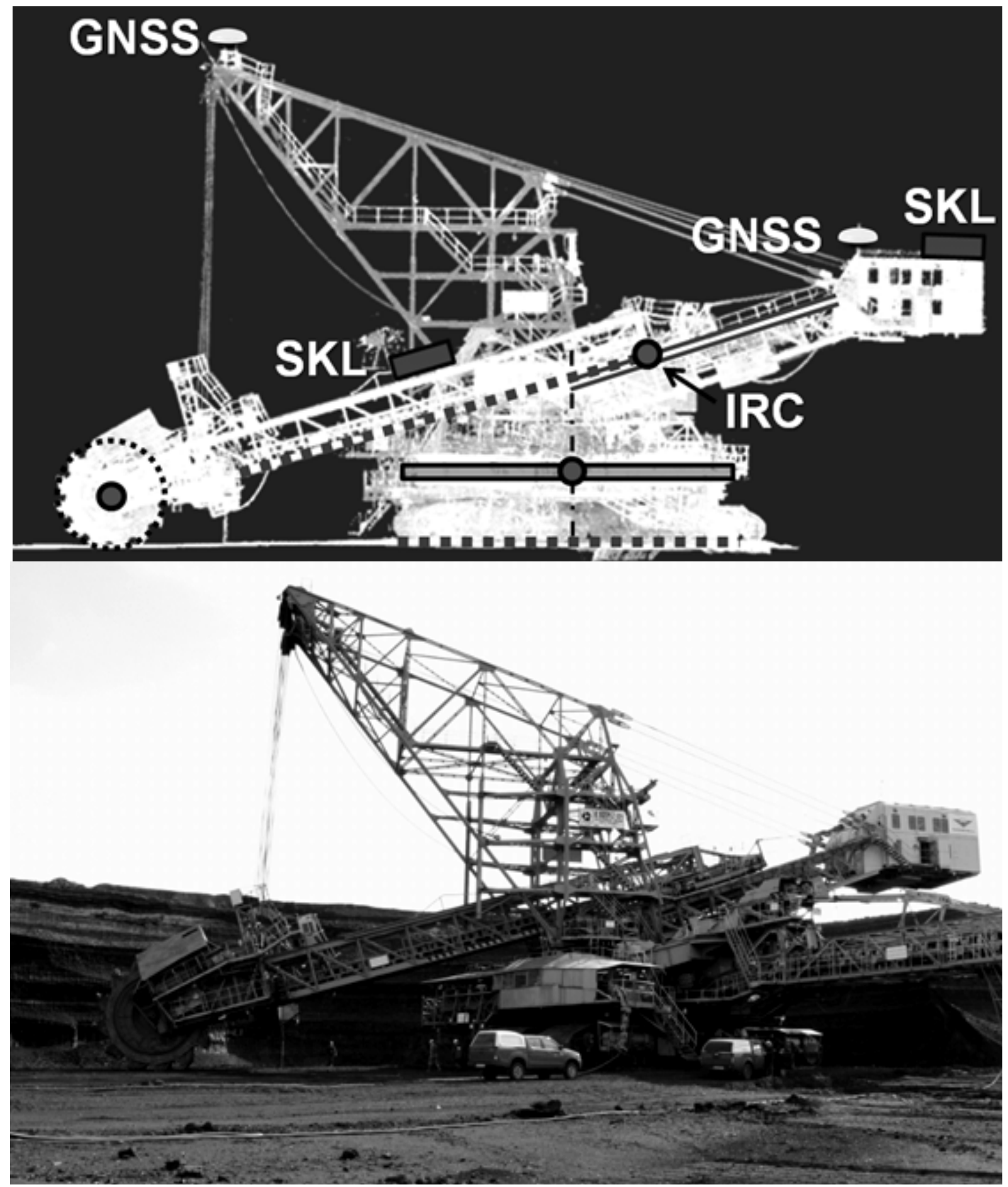

Fig. 1 Deployment of measuring instruments on a bucket wheel excavator (K800/N2/104): GNSS - receivers, SKL - inclinometers, IRC - incremental speed sensor.

the measuring instruments may vary with respect to the type and construction of the bucket wheel excavator. Some of the wheel excavators have a fixed boom (Scholze and Köhler, 2012).

For each bucket wheel excavator, a database of extracted masses is generated. This database records the wheel position every 5 seconds including the date and time of the calculation and the calculated volumes. If we know the geometric parameters of the excavator, the coordinates of the centre of the wheel and its radius and shape, we can define the boundary surfaces between the extracted and unextracted rocks. There is a simplified rule "Where the wheel has been, there cannot be any rock" (Benndorf, 2015).

Geometric parameters are measured and related to the following structural elements: 


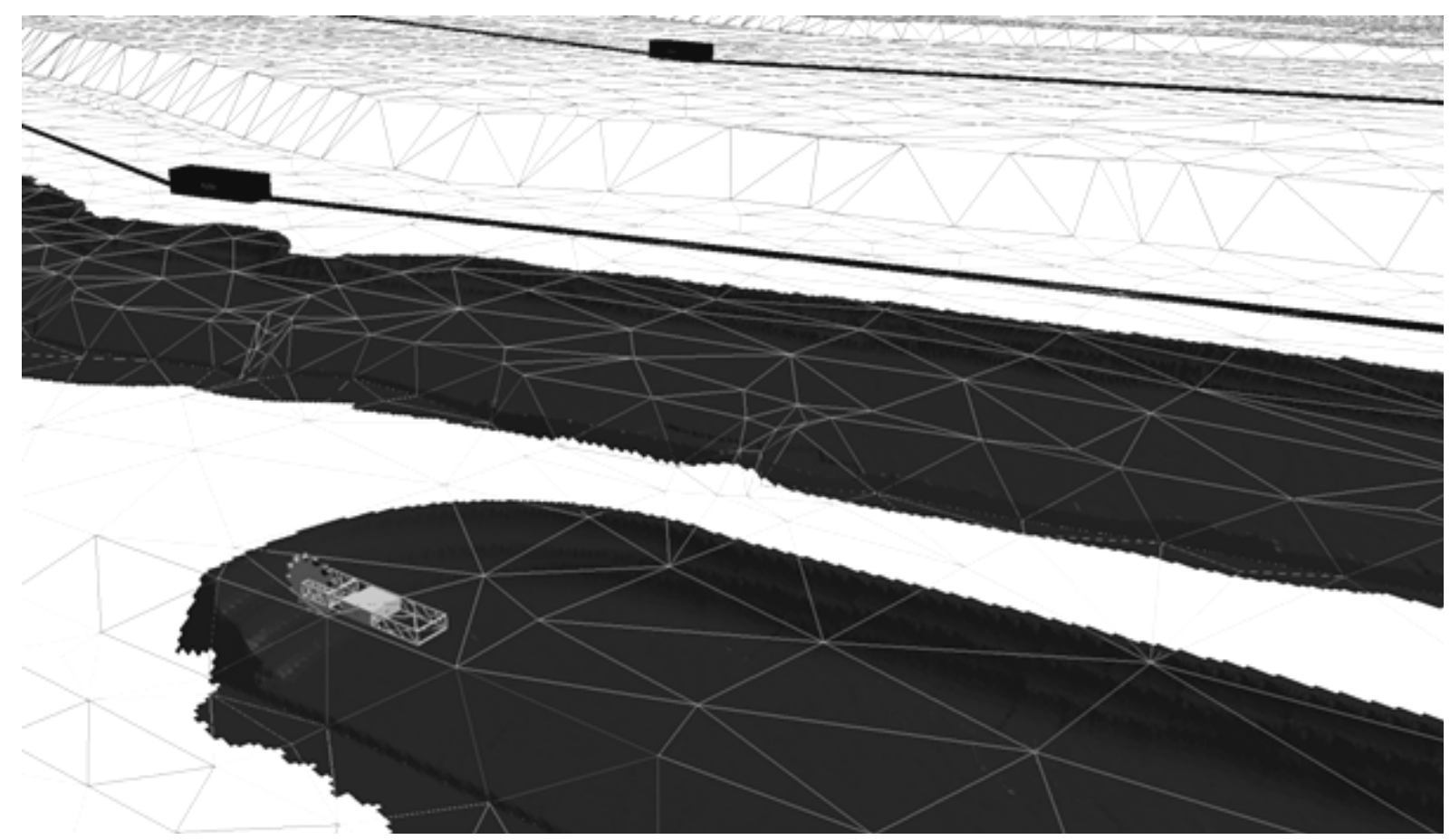

Fig. 2 Digital terrain model created from the current position of the 3D model of the KU322 bucket wheel excavator on 6 March 2018.

- the position of GNSS receivers,

- the centre of the wheel,

- the centre of the ball track,

- the direction of inclination of the wheel boom,

- the wheel boom joint,

- the bottom edge of chassis.

Bucket wheel excavators move above the common data space; a digital terrain model obtained from periodic measurements (aerial digital photogrammetry, UltraCam X, monthly cycle; Fig. 2). This measurement method was also used to check the volume calculation from the data obtained using the real-time mining control system (Rucký, 1997).

To calculate the spatial position of the centre of the wheel, it is necessary to develop a suitable mathematical model, based on the geometric parameters determined on the basis of geodetic measurements and using 3D laser scanning technology. These are the distances of the individual gauges relative to each other and to the mechanical nodes of the excavator design. For each type of bucket wheel excavator, a unique mathematical model was created to define its movement in three-dimensional space, together with the design (diagram) of the geometric parameters required for mathematical modelling. Selected geometric parameters may vary according to the actual position of the wheel boom. All variables and some constant parameters will change when the excavator's upper structure is rotated if it is inclined. When creating the mathematical model, all variations of motion must be considered (Maňas, 2010).
Some nodal points are inside the excavator's construction, and it is technically impossible to target them using conventional geodetic methods. Bucket wheel excavators were therefore focused on the Leica Scanstation C10 3D laser scanner and Faro Focus 3D. In the computer model, vectorization, localization of nodal points (e.g. of the wheel centre and diameter, joint of the boom, centre of the spherical track, edges of the caterpillar chassis, GNSS receivers, etc.) were carried out, and the measurement of other geometric parameters defining the movement of the excavator in 3D (Figs. 3 and 4).

Differences between the initial volume obtained from the calculation from photogrammetric backgrounds and the GNSS application method are minimal. For instance in the case of the SchRS $1320 / 110$ bucket wheel excavator, the difference in the volume of the extracted masses was $-0.3 \%$ in one month, and in the case of the bucket wheel excavator KU800/20 and the identical cycle, the difference was $+2.4 \%$. The reference model is the digital terrain model based on photogrammetric measurements. The measurement results are more accurate than the values obtained from the belt weights. Compared with the band balance, the difference was more significant and ranged between $-13.9 \%$ and $-11.4 \%$ (Sládková et al., 2012).

During the development of the system, there were continuous checks of the accuracy of the system by geodetic orientation. Direct measurement of the centre of the wheel axle was not possible because it is a point that is inside the wheel and it is technically impossible to survey it. A procedure was chosen in 

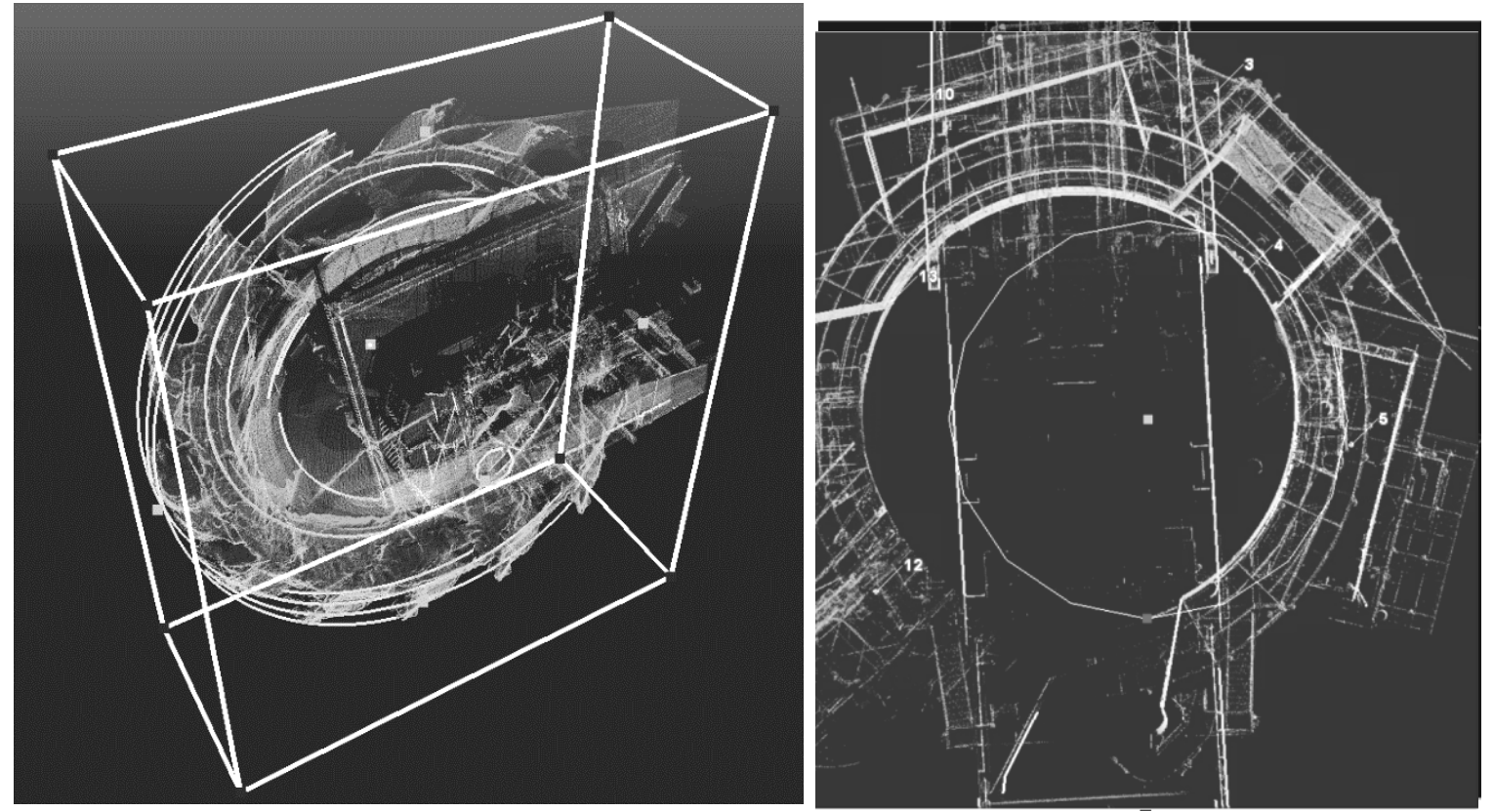

Fig. 3 Vectorization of the point cloud of the SchRs 1550 bucket wheel excavator. Determination of the wheel centre and diameter and the spherical track centre.

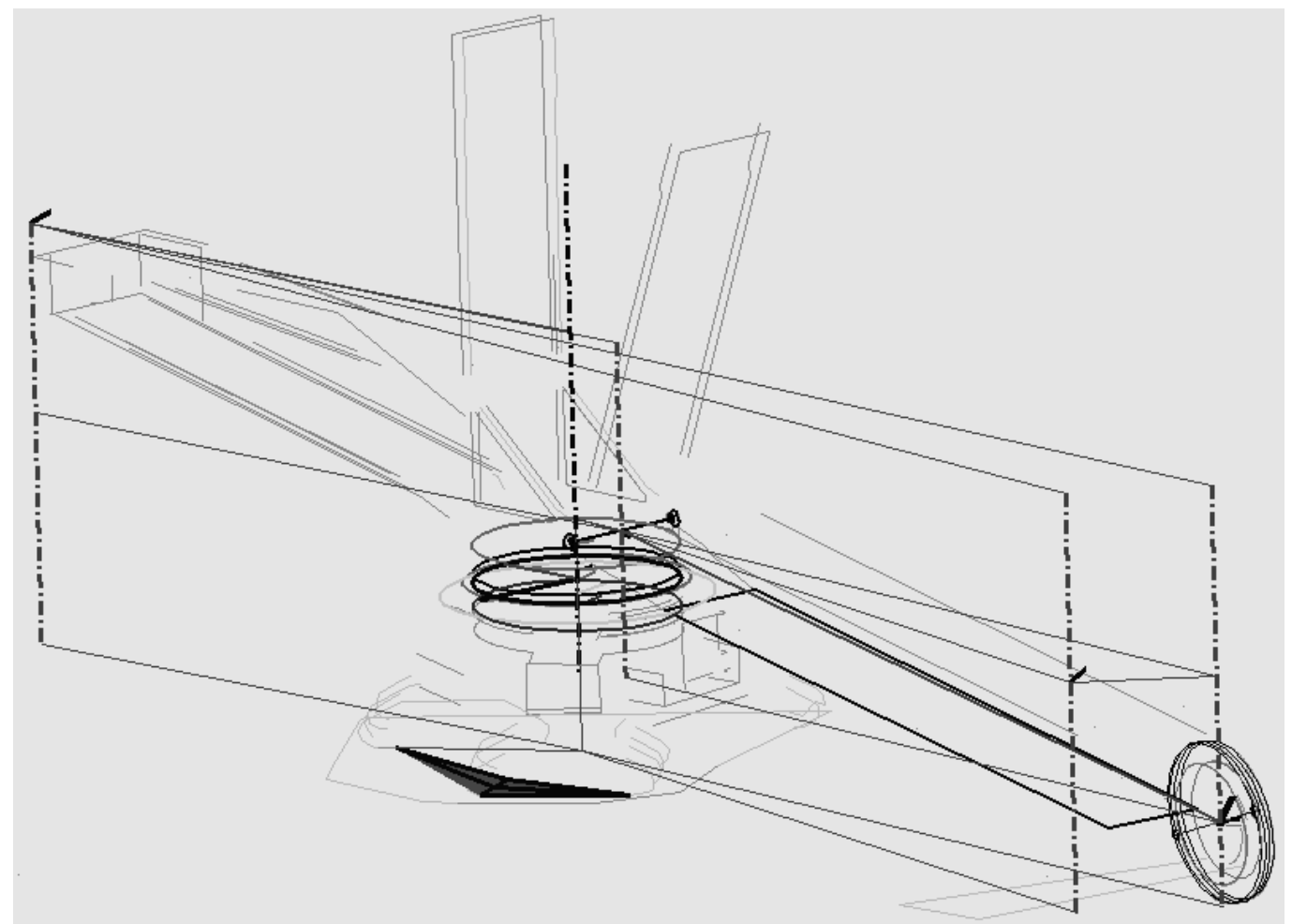

Fig. 4 Vector model of the SchRs 1550 bucket wheel excavator. 


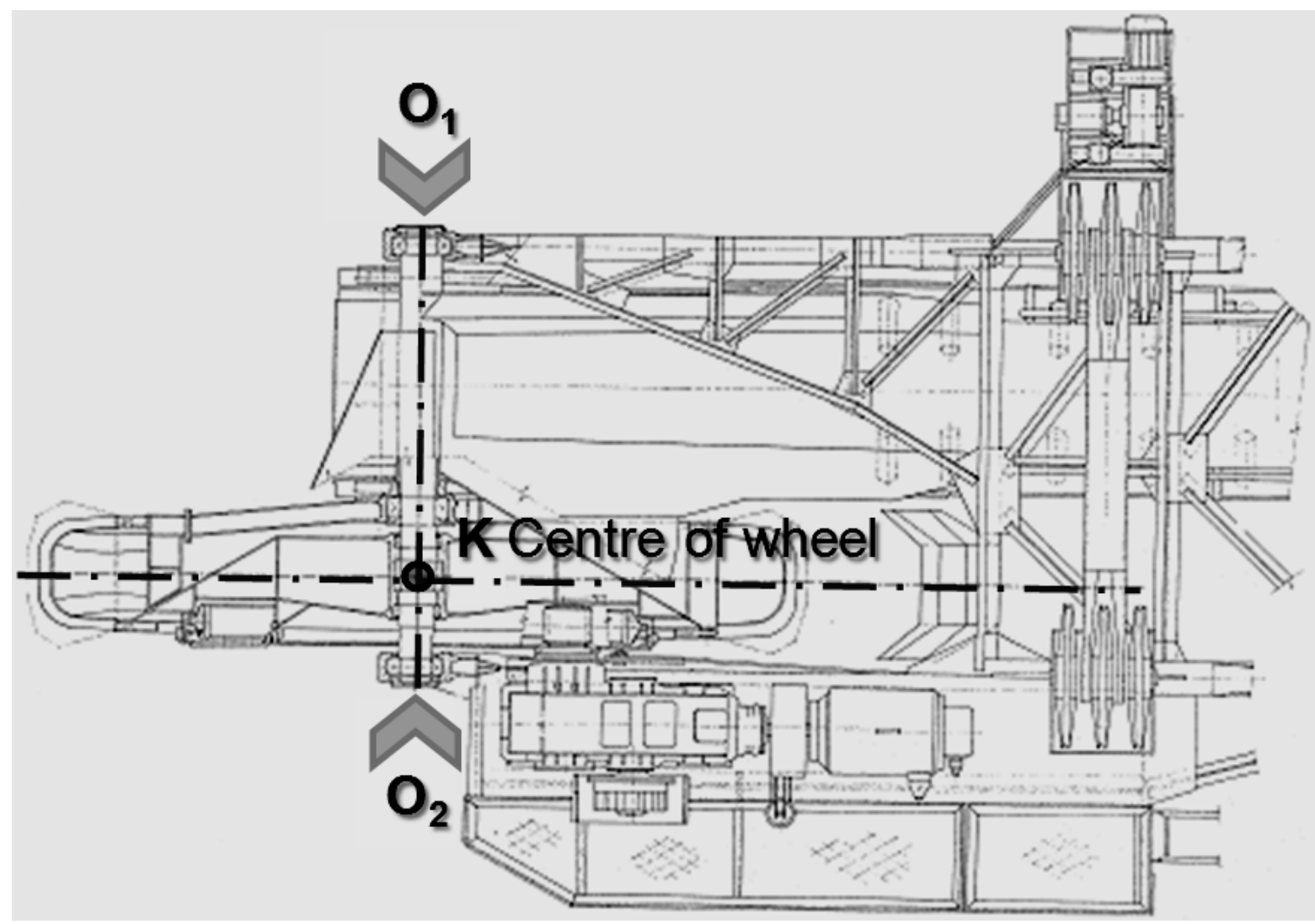

Fig. 5 The position of the wheel centre.

Table 1 Results of control at Nástup Tušimice mine - differences.

\begin{tabular}{lcr}
\hline Excavators & $\mathbf{O}_{\mathbf{x v}}[\mathrm{m}]$ & $\mathbf{O}_{\mathbf{z}}[\mathrm{m}]$ \\
\hline K800/103 & 0.37 & 0.01 \\
K800/104 & 0.38 & 0.06 \\
KU300/64 & 0.31 & -0.02 \\
KU300/76 & 0.08 & -0.08 \\
KU300/88 & 0.22 & -0.06 \\
KU300/89 & 0.47 & 0.15 \\
SchRs1550/109 & 0.20 & 0.27 \\
KU800/106 & 0.66 & -0.06 \\
SchRs1320/110 & 0.25 & -0.05 \\
\hline
\end{tabular}

which the centres of both ends of the wheel axis, which are available for surveying, were surveyed horizontally and vertically. These are points $\mathrm{O} 1$ and O2 (Fig. 5; Vrublová et. al., 2016).

There were measured standpoints for measurements the points $\mathrm{O}_{1}$ and $\mathrm{O}_{2}$ by the GNSS apparatus using the same transformation key (the same reference station) as used by GNSS receivers that are part of the excavator system. From the standpoint there were measured points $\mathrm{O} 1$ and $\mathrm{O} 2$ by electronic tachymetres and from the position of the wheel centre in relation to (it is usually not in the middle of the axis) the surveyed points $\mathrm{O}_{1}$ and $\mathrm{O}_{2}$ and, he calculated the coordinates of centre of the wheel axes $X_{K}, Y_{K}$ and $Z_{K}$ (point $K$ ). For simplicity, the coordinates obtained by the check survey geodesy were considered correct. At the same time, the coordinates of the centre of the $\mathrm{X}_{\mathrm{K}}, \mathrm{Y}_{\mathrm{K}}$ and $\mathrm{Z}_{\mathrm{K}}$ wheel axes calculated from the measurement of the measuring instruments on the excavator at the time of the check orientation were deducted from the realtime wheel tracking system database. Comparison of coordinates obtained from the system for the center axis of the wheel and the geodetic measurement are in Table 1. The $\mathrm{O}_{\mathrm{xy}}$ differences represent the horizontal difference, and $\mathrm{O}_{\mathrm{z}}$ is the vertical difference.

Updating the digital quarry model and real-time volume calculations, assigning the current position of the wheel to the positionally identical layers of the mineral (coal), and comparing the wheel's spatial 


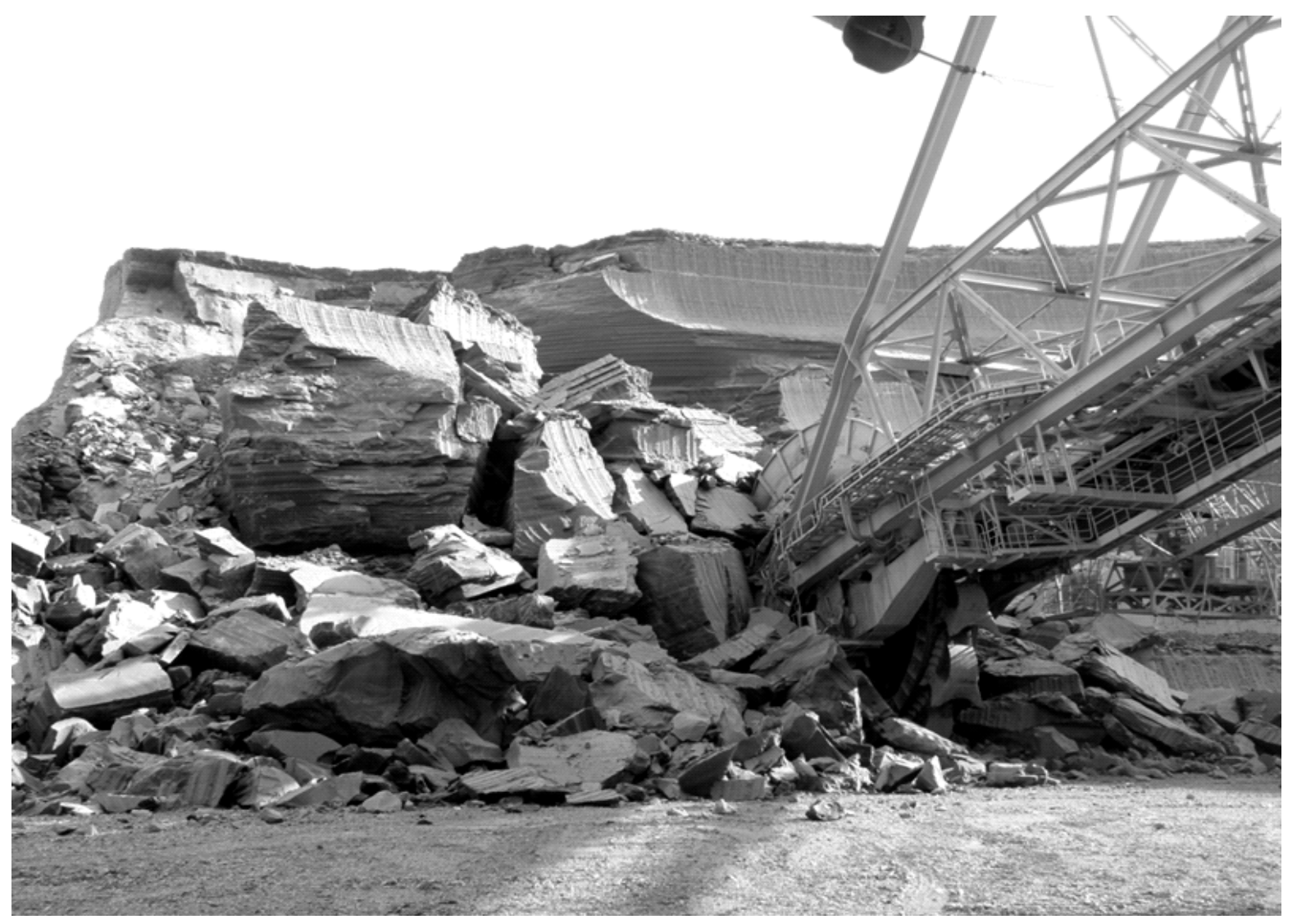

Fig. 6 Sudden landslide or rockslide could damage the excavator (Most Basin, Bílina Quarry on 11 May 2009).

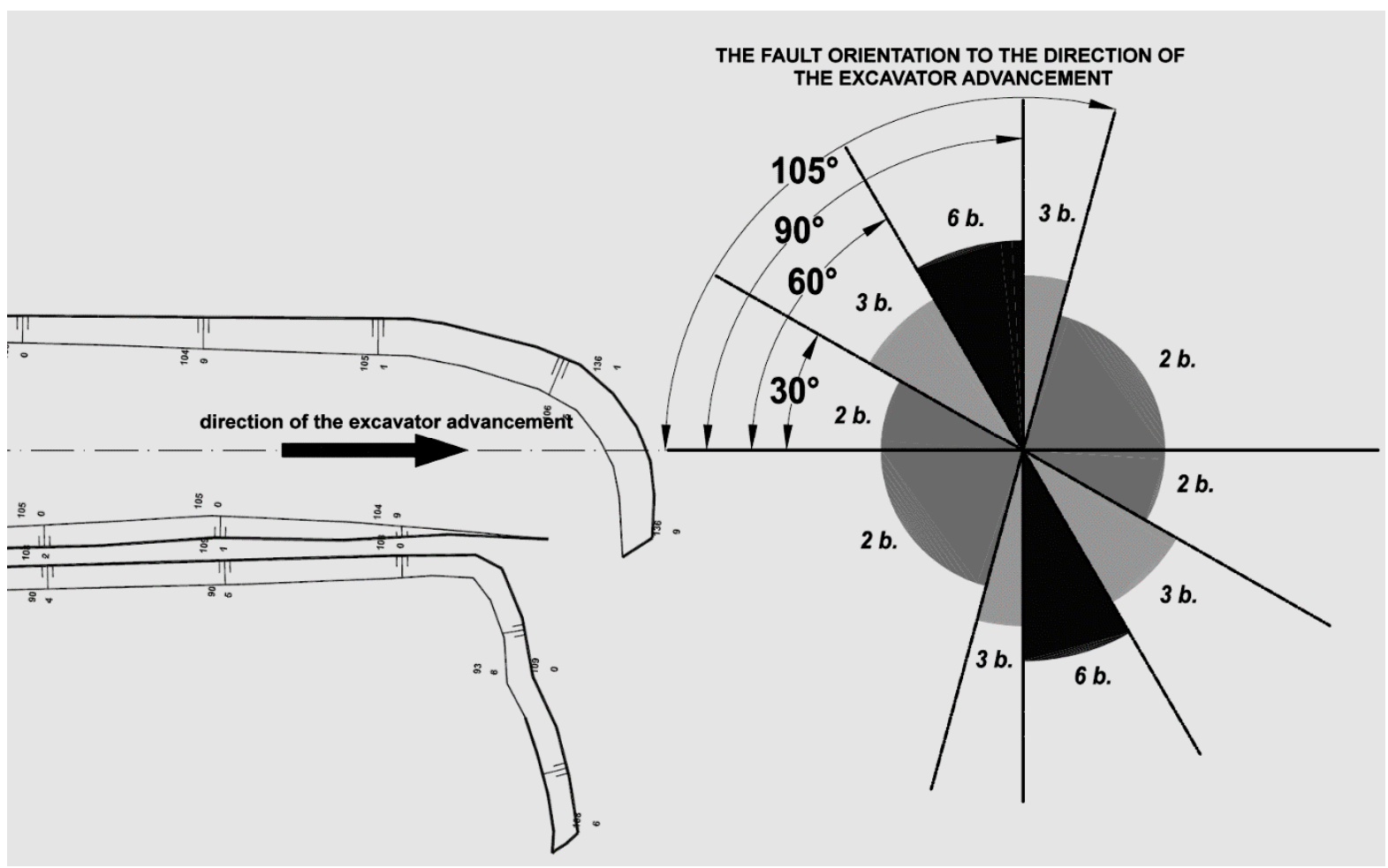

Fig. 7 Graphical representation of the influence of the fault orientation to the direction of the excavator advancement. 


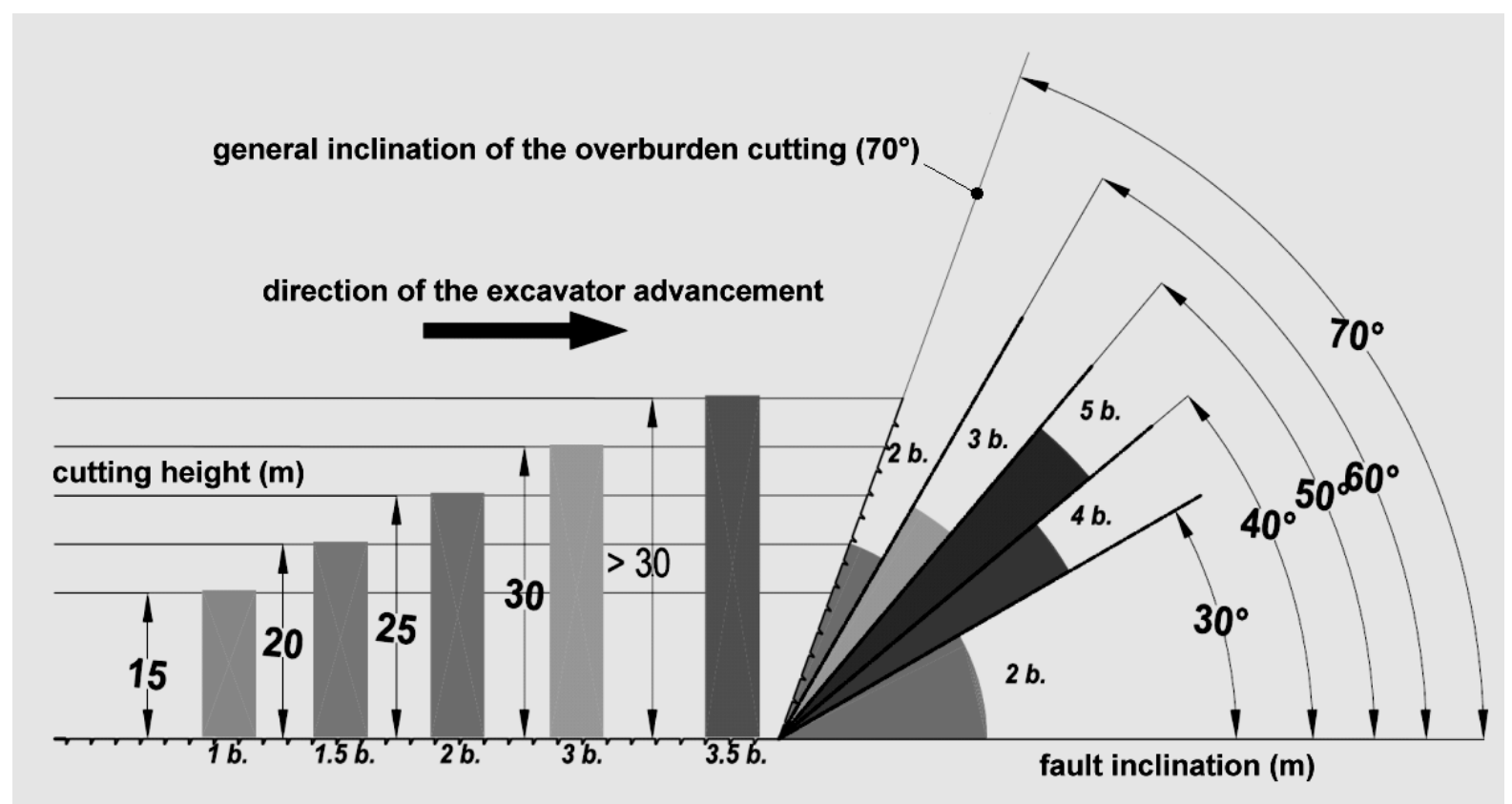

Fig. 8 The principle of risk assessment deriving from the direction of the disturbance in relation to the excavator advancement and cutting height.

position with the planned mining proposals, are the main methods and procedures for obtaining the information for the subsequent monitoring and management of the mining process. At present, in Severočeské doly a.s. a real-time spatial excavator system was used on 22 bucket wheel excavators.

\section{SPATIAL DEFINITION, GEOMETRIZATION AND CATEGORIZATION OF TECTONIC DISTURBANCES ENDANGERING THE SAFETY OF WORK DURING SURFACE MINING OF LIGNITE}

The described issue concerns the area of the Most Basin. In detail, the geology of the Most Basin is discussed in (Pešek et al., 2010). One of the most significant security risks influencing the technological process of coal mining in surface conditions in the conditions of the Tertiary Most Basin is represented by rockslides and landslides. Figure 6 is a photo of a landslide to the K2000/101 excavator, which took place on 11 May 2009. The wheel was damaged, and the excavator's upper structure was shifted. The crew of the giant machine was also at risk (Fig. 7).

The cause of the sudden landslide was a tectonic disturbance - a fault. Even though the tectonic disturbances were mapped in the period before this slide, it was decided to create a more in-depth system that would not only systematically search and geometrize these geological structures, but also evaluate and categorize them from the point of view of the danger of landslides and their impacts on occupational safety. The expert opinion "Draft classification of tectonic faults in view of their risk level for the process of large bucket wheel excavators" was drafted (Horák, 2009). Its result is the creation of a tectonic fault point system with risk assessment for bucket wheel excavator procedures.
The following main factors of the point system were determined for fault classification (Figs. 7 and 8):

- fault inclination angle,

- orientation of the disturbance (fault) direction in relation to the direction of the excavator advancement,

- cutting height,

- the direction of inclination of the wheel boom,

- $\quad$ nature of the fault area.

Tables 2 to 5 show a point system of tectonic disturbances-faults in terms of their risk level for the advancement of large bucket wheel excavators. This categorization system is necessarily highly subjective because it responds to the specific geological structure of the sedimentary lignite deposit and the experience of geologists directly at the site (Doly Bílina Severočeské doly a.s.).

The overall degree of risk that characterizes the tectonic break can be calculated by multiplying the number of points of the individual sub-factors:

\section{Total risk $=$ A x B x C x D}

According to the number of achieved points of the overall degree of risk to occupational safety, three groups of tectonic breaks were allocated (Table 6).

In total, the number of points for the level of risk can be in the range of $4-135$ points on slopes up to $30 \mathrm{~m}$ high. On slopes over $30 \mathrm{~m}$, the maximum can reach 157.5 points. When approaching a hazardous site, the operator of the excavator will act according to a pre-prepared scenario. It is clear from Table 5 that in the medium risk category, the choice of the measures will depend largely on the operator of the excavator who will have to be properly trained and timely 
Table 2 The disturbance orientation factor to the direction of the excavator advancement - Parameter A.

\begin{tabular}{cccccc}
\hline Angle $\left({ }^{\circ}\right)$ & Up to 30.0 & $30.1-60.0$ & $60.1-90.0$ & $90.1-105.0$ & $105.1-180.0$ \\
\hline Points & $\mathbf{2}$ & $\mathbf{3}$ & $\mathbf{6}$ & $\mathbf{3}$ & $\mathbf{2}$ \\
\hline
\end{tabular}

Table 3 The disturbance inclination factor - Parameter B.

\begin{tabular}{cccccc}
\hline Angle $\left(^{\circ}\right)$ & Up to 30.0 & $30.1-40.0$ & $40.1-50.0$ & $50.1-60$ & Above 60.0 \\
\hline Points & $\mathbf{2}$ & $\mathbf{4}$ & $\mathbf{5}$ & $\mathbf{3}$ & $\mathbf{2}$ \\
\hline
\end{tabular}

Table 4 The cutting height factor - Parameter C.

\begin{tabular}{cccccc}
\hline Height $(\mathrm{m})$ & Up to 15.0 & $15.1-20.0$ & $20.1-25.0$ & $25.1-30.0$ & Above 30.0 \\
\hline Points & $\mathbf{1}$ & $\mathbf{1 . 5}$ & $\mathbf{2}$ & $\mathbf{3}$ & $\mathbf{3 . 5}$ \\
\hline
\end{tabular}

Table 5 The factor of the fault area character - parameter D.

\begin{tabular}{ccccc}
\hline Description & $\begin{array}{c}\text { Simple slickenside without } \\
\text { shifting the blocks }\end{array}$ & $\begin{array}{c}\text { Simple slickenside with } \\
\text { shifting }\end{array}$ & Fault zone & Main fault line \\
\hline Points & $\mathbf{1}$ & $\mathbf{1 . 2}$ & $\mathbf{1 . 3}$ & $\mathbf{1 . 5}$ \\
\hline
\end{tabular}

Table 6 The division of tectonic breaks according to safety risks.

\begin{tabular}{clc}
\hline Risk level & \multicolumn{1}{c}{ Character of faults } & Points \\
\hline Low Risk & $\begin{array}{l}\text { In terms of sets of risk parameters, the fault will not cause problems during } \\
\text { mining }\end{array}$ & $4-30$ \\
\hline Medium Risk & $\begin{array}{l}\text { It presents a certain risk that can be eliminated without significant changes in } \\
\text { the planning of procedures, at maximum, the mining outputs will be reduced }\end{array}$ & $30-90$ \\
\hline High Risk & $\begin{array}{l}\text { The fault is considered to be very hazardous for many reasons, so it is } \\
\text { necessary to take a number of measures for its successful and safe extraction } \\
\text { at the stage of preparation }\end{array}$ & $90-135$ \\
\hline
\end{tabular}

warned before entering the hazardous site. In sections with tectonic disturbances, it is forbidden to carry out block mining by moving the wheel boom from top to bottom. The giant machine driver extracts the block by cutting horizontal benches up to the thickness of $6 \mathrm{~m}$. The first and second bench is mined to the maximum reach of the wheel boom extension, always with the driver's cab in the upper position. After the front and side slopes have been relieved and excavating the upper benches, the giant machine will walk away (drive away) into the position for extraction of the bottom benches with the advancement to the bottom of the cut. The actual extraction of blocks with tectonic faults must be carried out under constant supervision. The technical supervision - the head miner will entrust a skilled mining worker (usually a member of the crew of the giant machine) with the permanent supervision. The head miner will check the side slopes twice before the giant machine advancement. For high-risk breaks (overall risk above 90), the degree of potential danger to the excavator is so high that there is an effort to avoid the risk entirely or to reduce the level of the total risk. From the past experience and evaluation of landslides, we can say that the most significant risk is the $60-90^{\circ}$ fault with respect to the axis of the excavator advancement, with a $40-50^{\circ}$ disturbance inclination and a cutting height of $30 \mathrm{~m}$ (exceptionally over $30 \mathrm{~m}$ ). The situation is still complicated due to the character of the fault area. In such a case, the measures are specified in advance, at the planning stages of quarterly and monthly mining advancement. To minimize the increased risk, preliminary mining measures are appropriate. This may be a change in the direction of the excavator advancement in relation to the disturbance inclination, the reduction in the cutting height, or the planning of the excavator advancement at an elevated travel area beyond the tectonic fault. This reduces the cutting height and thus reduces the overall risk. Subsequently, the lower part of the cut is extracted up to the originally planned height level.

\section{APPLICATIONS FOR THE ELIMINATION OF RISKS CAUSED BY TECTONIC DISORDERS}

The basic database of tectonic disorders is created in Excel ${ }^{\circledR}$. The following data are essential for the purpose of generating fault areas: fault name, $Y$, $\mathrm{X}, \mathrm{Z}$ point of reference coordinates (coordinates of the point through which the tectonic disturbance plane passes), fault inclination direction, the value of 


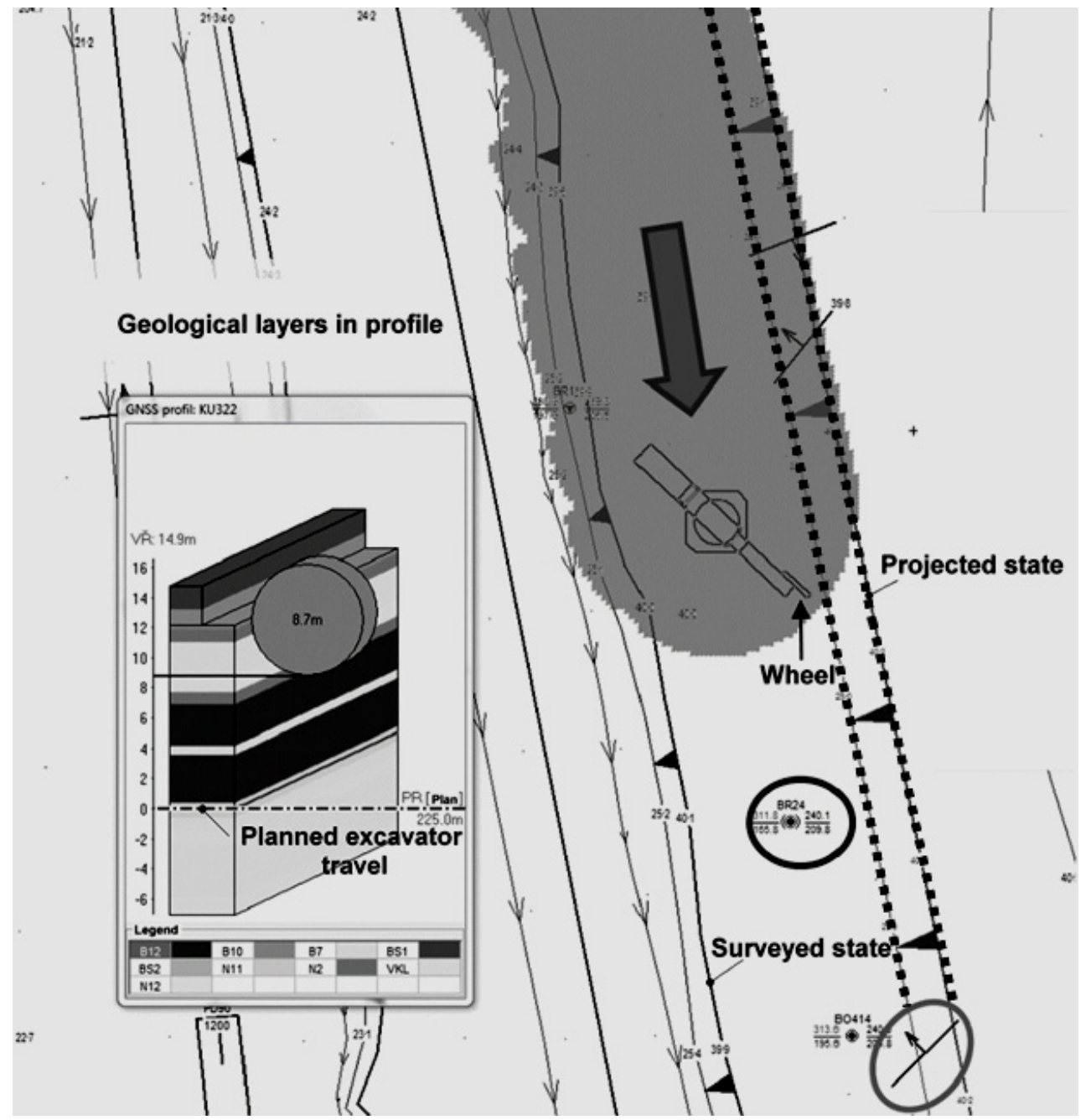

Fig. 9 Current position of the excavator in relation to geological structures and dangerous objects, V̌r, P̌̌, plan.

magnetic declination at the given site, fault inclination and the vertical and horizontal reach of the fault. There are other data in the database, but they can be considered as supplementary, not necessary to create areas. These are, for example, data about the author of the measurement, the mineralization of the faults, the direction and the inclination of the striations. In the Mine Model program, the database of tectonic disturbances-faults is imported from a *.xls file. The retrieved data must be located in the prescribed format in the 1 st book, which is considered to be a working book. Each table field must contain the corresponding data (Jiránková, 2012).

The program then generates a graphical representation of the intersection of the fault area with the attached models. The fault object is formed by intersections of the fault area passing through the MASTER model (mostly oriented to the quarry state) and the REFERENCE model (the state planned for the next period) at the same time. A fault mark is also generated. Tectonic fault generation occurs at the same time for all records in the database.

Depending on what application is used, the use of tectonic fault information in the excavator advancement differs. The Mining Model application is used by mining managers. For them, the fault display is only informative. In the Mining Model program environment, the current position of the KU300/22 coal excavator on 5 January 2018 at 12:48 is shown in Figure 9. In the excavator advancement, the tectonic fault with the inclination of the fault is opposite the direction of the excavator advancement. The ellipse shows a bore with equipment left behind, which is an object that poses a risk to the excavator, such as cutting the rubber band. The planned state of the coal cut, including the altitude of the newly travel area of the excavator, is plotted with red lines in the Mining Model program (dotted line in Figure 9). The figure below shows a schematic profile of the coal seam with colour-differentiated layers; the colour shade indicates the different calorific values of coal in the original state $\mathrm{Qr}[\mathrm{GJ} / \mathrm{t}]$. At the same time, the red line indicates in the Mining Model program the altitude of the planned excavator travel (dot-dash line in Figure 9). VŘ: $14.9 \mathrm{~m}$ means the current cutting height. The cylinder expresses the wheel and numerical data in it the heel height of the wheel from the projected height level of the mining plain. The technical supervision 


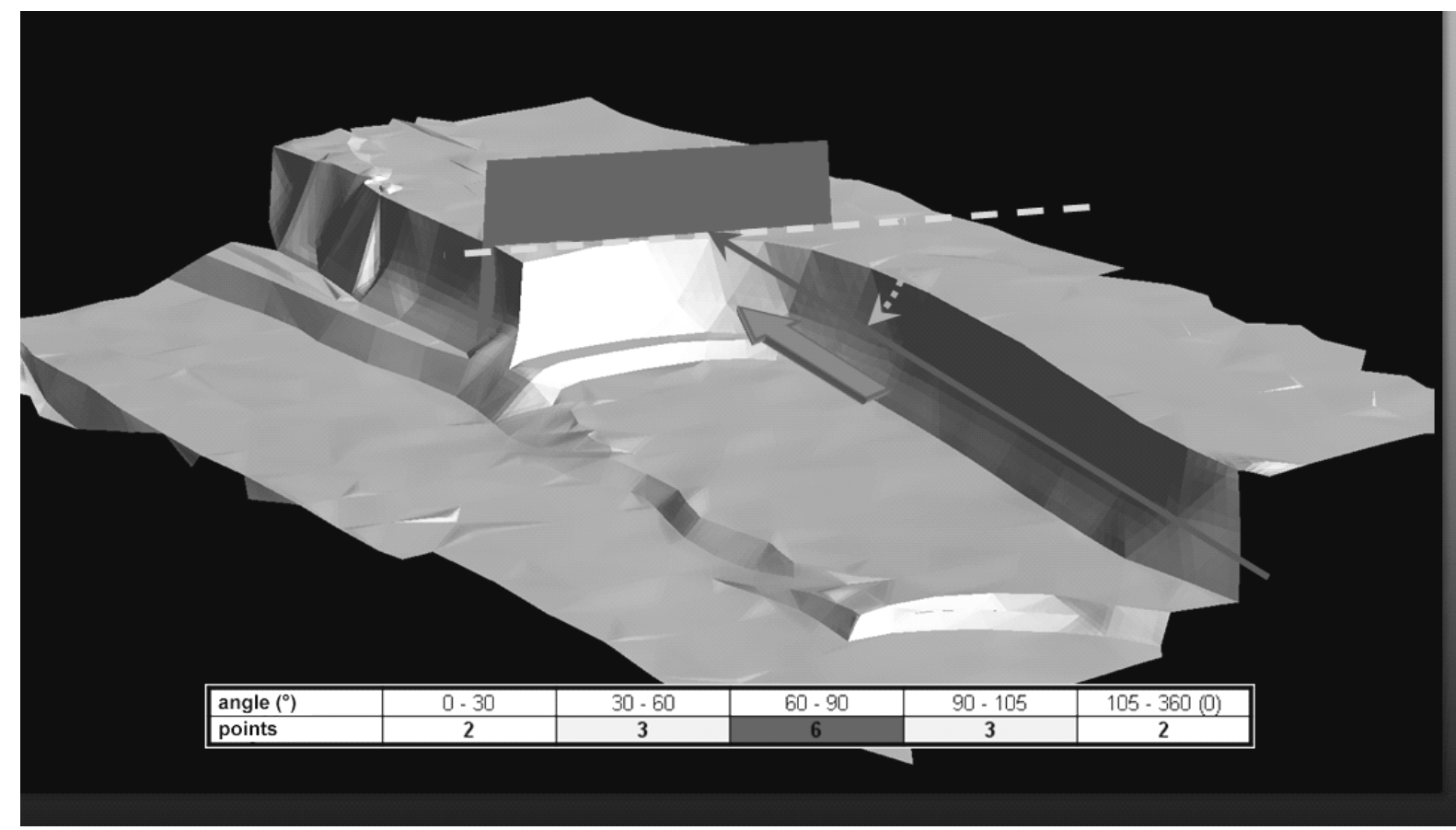

Fig. 10 Spatial representation of the principle of evaluating the break orientation to the direction of the excavator advancement.

can thus easily check if the cutting height is exceeded, or if the planned elevation level of the work plain is not met.

Figure 10 is a spatial representation of the principle of evaluating the orientation of the fault in relation to the direction of the excavator advancement as one of the risk factors that is a part of the assessment system for the overall risk caused by the geological structure. The angle of the fault direction in relation to the excavator's axis is between $60^{\circ}$ and $90^{\circ}$, which is the highest risk point in view of this criterion.

Giant machine drivers use the "GNSS - Cab" application, which is a certain simplification of the Mining Model program. However, the application, unlike the Mining Model, contains tools for assessing the risk of tectonic faults and their visualization. The giant machine driver is more aware of the danger of tectonic disturbance.

Figure 11 is an example of mining near a tectonic fault, as visualized in the GNSS cab program. The wheel boom is replaced in the calculation program by a vector having an end point on the part of the wheel that is furthest from the vertical axis of the excavator. For safety reasons, this vector is further extended by $1 \mathrm{~m}$ for further calculations for this application. The wheel boom moves and this end point has its coordinates $\mathrm{X}$ and $\mathrm{Y}$ in the expressed coordinate system. All tectonic faults with their parameters which assess their risk are stored in the database (see Tables 1-4). Faults are also spatially defined. If the end point of the wheel boom vector lies in the ground plane of a fault, the overall risk is calculated. In our case:

\section{Overall risk $=\mathbf{A} \times \mathbf{B} \times \mathbf{C} \times \mathbf{D}=$ $=5 \times 3 \times 1.5 \times 1.5=33.75(33.8$ in Figure 11)}

The driver of giant machine can see a schematic layout of the excavator and the tectonic fault on the screen. When approaching a fault, the ground plan of the fault will turn black and the following notice will appear at the bottom: WARNING: The wheel is in the geological fault area (33.8 points). According to the classification of tectonic faults mentioned in chapter 3.1 , the overall risk for this particular fault near which the KU800/98 excavator was mining on 22 December 2015 was calculated at 33.8 points. According to Table 5, this means medium risk, and the giant machine driver subsequently implements predetermined measures in the technological process.

\section{CONCLUSION}

The article describes the risk assessment system of tectonic breaks at Severočeské doly a.s.; in practice it has been applied since 2011, and since 2015 it has been used in the excavator wheel tracking system applications. The system has proven itself useful and since 2011 there have been no landslides that would have such a destructive impact as the landslide on the K2000/101 excavator on 11 May 2009. The emphasis is mainly on prevention. For highly hazardous faults, in most cases, the excavator advancement has been preconditioned so that the risk is as low as possible. The tectonic fault database is constantly updated (several thousand tectonic disorders). Even if all measures are taken and the above system is used, it is not possible to completely eliminate the landslides. A proper investigation of the causes of landslides and 


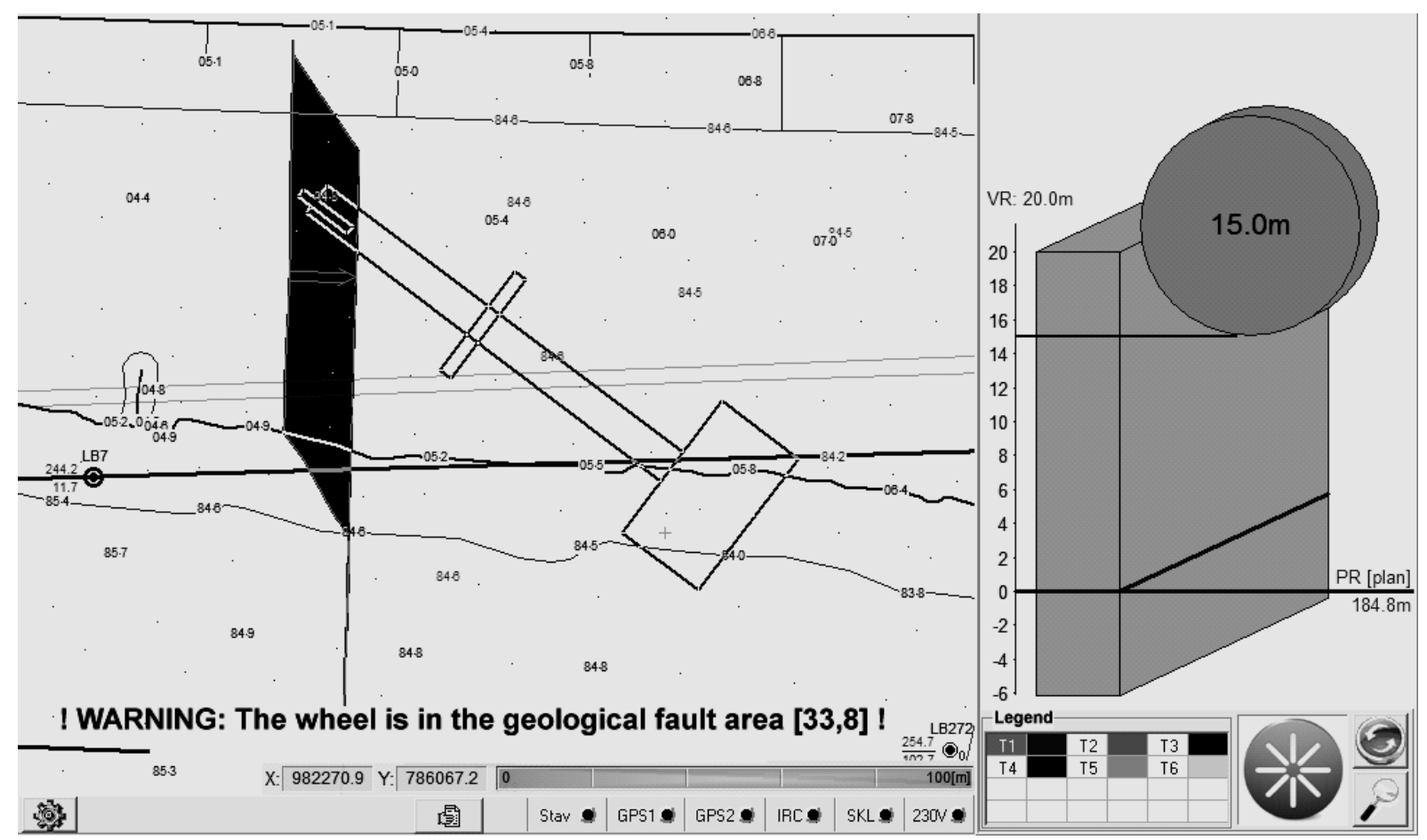

Fig. 11 Graphical representation of the effect of the fault orientation on the direction of the KU800/98 excavator.

their thorough mapping serves to clarify the original applicable measures.

\section{ACKNOWLEDGMENTS}

This article was written in connection with project Institute of clean technologies for mining and utilization of raw materials for energy use Sustainability program. Identification code: LO1406. Project is supported by the National Programme for Sustainability I (2013-2020) financed by the state budget of the Czech Republic.

\section{REFERENCES}

Benndorf, J.: 2015, Making use of online production data: Sequential updating of mineral resource models. Math. Geosci., 47, 5, 547-563.

DOI: $10.1007 / \mathrm{s} 11004-014-9561-y$

Horák, L: 2009, Draft classification of tectonic faults in view of their risk level for the process of large bucket wheel excavators. GeoTec., (in Czech).

Jiránková, E.: 2012, Utilisation of surface subsidence measurements in assessing failures of rigid strata overlying extracted coal seams. Int. J. Rock Mech. Min. Sci., 53, 111-119.

DOI: $10.1016 /$ j.ijrmms.2012.05.007

Maňas, I.: 2010, The principle of generating surfaces and calculating volumes in the Mining Model. Technical Report to the program, (in Czech).

Pešek, J. et al.: 2010, Tertiary basins and lignite deposits in the Czech Republic. Česká geologická služba, 438 pp., (in Czech).
Rucký, P.: 1997, Comprehensive verification of GPS application on wheel excavators of the company DNT - SD, a.s. for operational management and control of coal and overburden excavation. VÚHU Research Report, No. 262/97, (in Czech).

Scholze, P. and Köhler, U.: 2012, Komplexe steuerungsfunktionen und betriebsführungsinstrumente in den tagebauen der Vattenfall Europe Mining AG. World of Mining - Surface and Underground, 64, 1, 31-39.

Sladková, D., Kapica, R. and Vrubel, M.: 2011, Global navigation satellite system (GNSS) technology for automation of surface mining. Int. J. Min. Reclamat. Environ., 25, 3, 284-294.

DOI: $10.1080 / 17480930.2011 .608879$

Sladková, D., Kapica, R. Vrubel, M. and Michalusová, M.: 2012, Calculations of volumes of excavated masses in real-time. Hnědé uhlí, Most, Výzkumný ústav pro hnědé uhlí, 2, 10-15, (in Czech).

Vrublová, D., Kapica, R., Gibesová, B., Mudruňka, J. and Struś, A.: 2016, Application of GNSS technology in surface mining. Geodesy and Cartography, 42, 4, 122 128. DOI: $10.3846 / 20296991.2016 .1268433$

Vrublová, D., Kapica, R. and Jurman, J.: 2012, Methodology devising for bucket-wheel excavator surveying by laser scanning method to determine its main geometrical parameters. Geodesy and Cartography, 38, 4, 157-164.

DOI: $10.3846 / 20296991.2012 .757438$ 